\title{
LA HABITACIÓN CONTIGUA. KAFKA, EL PSICOANÁLISIS Y EL LABERINTO DE LA INMANENCIA ${ }^{1}$
}

\author{
Cristóbal Durán Rojas \\ Universidad Andrés Bello \\ Santiago de Chile \\ cristobal.duran@unab.cl
}

\begin{abstract}
RESUMEN / ABSTRACT
En este artículo nos proponemos examinar la compleja relación que ha mantenido la obra de Kafka con la lectura e interpretación psicoanalítica. Si bien el psicoanálisis ha puesto en entredicho su posibilidad de ser directamente aplicado a la literatura, y ha apelado a una co-implicación entre ambos dominios, no por ello ha podido abstenerse de encontrarse a sí mismo en sus lecturas literarias. El caso de Kafka es ejemplar, en la medida en que parece darle al psicoanálisis la posibilidad de reconocer sus operaciones de lectura relativas a la centralidad de la ley y del deseo en la propia matriz del texto literario. Intentaremos mostrar que, a partir de las posibilidades -paradójicas ciertamente- ofrecidas por el psicoanálisis, es posible abrirlo hacia una lectura puramente inmanente del texto kafkiano, donde este puede ser visualizado como un laberinto hecho de contigüidades, que van aplazando la unificación del deseo y que lo van desplegando hacia conexiones siempre inéditas.
\end{abstract}

Palabras ClaVE: Kafka, psicoanálisis, deseo, contigüidad, laberinto.

\section{THE CONTIGUOUS ROOM. KAFKA, PSYCHOANALYSIS AND THE LABYRINTH OF IMMANENCY}

In this article we attempt to examine the complex relationship that Kafka's work has had with psychoanalytic reading and interpretation. Although psychoanalysis has called into

$1 \quad$ El presente trabajo es un resultado del Proyecto FONDECYT $\mathrm{N}^{\circ} 1201271$ (ANID, Gobierno de Chile), "La variación continua como determinación diferencial de una multiplicidad: el aporte de Gilles Deleuze a la reformulación del problema metafísico del continuo". Investigador responsable: Cristóbal Durán. 
question its possibility of being directly applied to literature, and has appealed to a coinvolvement between both domains, it has not been able to refrain from finding itself in its literary readings. Kafka's case is exemplary, insofar as it seems to give psychoanalysis the possibility of recognizing its reading operations relative to the centrality of law and desire in the very matrix of the literary text. We will try to show that from the possibilities -paradoxical certainly-offered by psychoanalysis it is possible to open it towards a purely immanent reading of the Kafkaesque text, where it can be visualized as a labyrinth made of contiguities, which postpone the unification of desire and which they are unfolding towards ever new connections.

Keywords: Kafka, psychoanalysis, desire, contiguity, labyrinth.

Recepción: 30/11/2020

Aprobación: 29/12/2020

\section{INTRODUCCIÓN}

El caso de Kafka parece constituir un verdadero "caso" para el psicoanálisis. El peso de un imaginario psico-familiar y fuertemente edipizado nos presentaría a Kafka, por antonomasia, como quien ha hecho de una vida de sujeciones un imperativo para la escritura. Sea para intentar escapar de ellas, como para mantenerse atado irrestrictamente a su mandato, sus textos parecen mostrarnos un caso nítido de un intento de resolver los conflictos de la vida psíquica por la vía de la literatura. Enfrentarse a la lectura de Kafka, como intentaremos mostrar, supone una dificultad tanto mayor por cuanto sus textos no solo parecen facilitar lecturas de aplicación del psicoanálisis al texto literario, sino que, al mismo tiempo, dificultan dichas operaciones de lectura al ofrecer parábolas que no podríamos captar inmediatamente con un talante alegórico que nos permite generar una transferencia de un sentido constituido a otro por constituir, que tendría las características similares a su modelo.

Dado que los escritos de Kafka parecen interrumpir la inteligibilidad de un significado trascendente a ellos -y con el cual se habría querido dotarlos de un carácter comprensivo- no es extraño que desde una lectura psicoanalítica se haya querido mostrar que algunos de sus escritos abren una brecha que interrumpe, no solo el dominio del significado y del sentido común, sino también interrumpen la supuesta continuidad de una lectura inmanente. En tanto esta última pareciera evitar los recursos explicativos exteriores al texto mismo -y que, en esa misma medida, podría evitar la subsunción del psicoanálisis a un plano desde donde extraer un significado disponible de antemano para la lectura de escritos literarios-, pareciera ser preferible si el psicoanálisis quiere dejar de ser una mera instancia de aplicación de sus conceptos y tomar así distancia del llamado "psicoanálisis silvestre". 
La lectura psicoanalítica, con su atención a las brechas y fracturas que hacen flaquear el sentido en su totalidad, tomaría nota de la demolición del sujeto, que ya advertía Adorno al leer a Kafka, y que mostraba a los textos kafkianos como una especie de imagen enigmática hecha de trozos dispersos, despojados de todo código o doctrina de interpretación. Incluso, podríamos decir, la brecha o la marca de interrupción es también lo que define a la literalidad como litoralidad en el sentido que le da Lacan a este término: aquello por lo cual se marca el agujero en el saber y, con ello, el significado se va erosionando y desbarrancando (Lacan 17; Biswas 184). A pesar de esto, y dado que el texto de Kafka pone de relieve una relación con la ley (y, por consiguiente, un deseo por la ley y contra la ley), una lectura psicoanalítica correría el riesgo de caer en un impasse: encontrarse a sí misma al leer los relatos de Kafka, situando su modo de comprender el deseo como sentido mismo del deseo kafkiano.

Producto de lo anterior, es preciso contemplar los elementos psicoanalíticos como parte de un ejercicio de lectura que no busque colmar las salidas propuestas por el texto de Kafka, y que, como mostraremos, dibujan un plano de lectura que constituye un verdadero laberinto de conexiones inéditas y de relaciones de contigüidad que son repuestas una y otra vez para evitar que la lectura de Kafka dependa de una unidad de sentido trascendente. Podríamos incluso imaginar a un Kafka clínico, siempre y cuando la clínica sea un arte que recoge las formas de todas las conexiones e inflexiones posibles que va tomando esta línea del deseo, y siempre y cuando sea un arte para pesquisar la parálisis de esa línea y sus atolladeros, sus continuidades y cómo las líneas de mayor pendiente arrastran a las demás (Deleuze y Parnet 134).

\section{EL PSICOANÁLISIS, LECTOR}

A pesar de su evidente interés por la literatura, de la cual hay copiosas referencias tanto en sus escritos como en su correspondencia, Freud sospechó del interés que podría tener el psicoanálisis para arrojar luz sobre las producciones artísticas. A pesar de eso, no dudaba de que el artista imponía un trabajo a sus mociones de deseo, y que las producciones del arte serían una reacción a las impresiones de infancia y a los avatares vitales del artista (Freud 417). Esta aparente causalidad se impondría por sobre la pregunta por la proveniencia de la "capacidad para crear" (417), lo que mantendría al psicoanálisis sujeto al esquema de la aplicación -como en el caso clásico de la lectura de Poe, hecha por Marie Bonaparte en 1933, que de inmediato Freud advirtió que no 
pretendía explicar el genio creativo (Felman 310)-y, con ello, se corría el riesgo de limitar el encuentro con la literatura a una instancia de anticipación o de confirmación de los descubrimientos clínicos.

El interés en la literatura se traducía entonces en una distancia. Como le confiesa a Jung, "un caso real y completo no puede ser narrado sino solo descrito" (Freud y Jung 141). Pero es preciso entender que esta distinción entre narración y descripción en realidad implica dos hipótesis de lectura. Freud crea una comprensión de la obra de arte como un texto por descifrar -como un texto sintomal-, pero lo hace explícitamente al expulsar la simple representación simbólica, y pensándolo primero como una formación de compromiso entre fuerzas diversas y heterogéneas (Kofman, L'enfance de l'art). De algún modo, Freud se habría encaminado a mostrar el parentesco y la distinción entre las producciones psíquicas por él descritas y la literatura, con un método "que introduce una continuidad donde, aparentemente, hay laguna, vacío, ruptura, disyunción: un lazo entre lo consciente y lo inconsciente, entre lo normal y lo patológico" (14).

Es cierto que no se puede afirmar sencillamente una aplicación del psicoanálisis a la literatura, que el mismo Freud no consentía. Sobre todo, porque el psicoanálisis se abocará a leer las brechas en una continuidad para hacerla posible. Eso supondría, en primera instancia, afirmar que la interpretación -y la lectura- del psicoanálisis no es solo respecto al significado preestablecido, y que el psicoanálisis ha abierto la vía para pensar de otro modo lo que la historia de la lectura ha dado en asumir y no cuestionar: el hecho mismo de que "la lectura es encontrar significado, que la interpretación sólo puede detenerse en lo significativo" (Felman 315). Sin duda, esto supone reafirmar el carácter enigmático que hay en el descubrimiento freudiano, y la necesidad de aproximarlo a la crítica literaria a partir de ello, lo que requerirá buscar en la literatura una idea menos psico-biográfica (Lacan 14).

Entre la narración y la descripción que Freud habría querido distinguir, ya no se puede confirmar una aplicación ${ }^{2}$, ciertamente, sino más bien, como lo ha planteado Felman, "una inter-implicación de cada una en la otra" (319). Esta precaución, sin embargo, no nos ahorra el espíritu impositivo

2 En el sentido en que sería una aplicación que se ejerce exteriormente sobre un campo que le sería en principio extraño. Sin embargo, también se podría pensar otro modo psicoanalítico de aproximarse a la aplicación, esta vez definida en contraste con la ejemplificación: "La aplicación importa algo del dinamismo de los dispositivos literarios a la teoría, mientras que la ejemplificación solo busca la confirmación de verdades preestablecidas" (Rabaté 66). 
que estaría en la voluntad de aplicar, y que quizá era lo que Freud quería evitar con su distinción. La aplicación se puede dar en distintos niveles, incluso advirtiendo analogías u homologías formales. Si se ha resistido el elemento psico-biográfico ello no implica abandonar la relación de una distancia controlable entre el psicoanálisis y la literatura. De este modo, el psicoanálisis se vería reflejado en sus operaciones en los escritos que lee, al tomarse como medida de lectura. Así se podría entender todo el análisis y la lectura hecha por Lacan de The Purloined Letter, de Poe, como "nada menos que una alegoría del psicoanálisis" (Felman 314), donde "la intervención de Dupin, quien restaura la carta a la reina, es entonces comparada con la intervención del analista, que libera al paciente del síntoma”.

Esta exterioridad en la relación entre psicoanálisis y literatura-que apunta a que su aproximación por la vía de la aplicación pareciera indicar la ruina de su carácter heterogéneo-, amenaza con borrar algo de la existencia de ambas, en tanto modos diversos de leer e interpretar. En la tesis de Bayard (2004), que busca aplicar la literatura al psicoanálisis, apelando a la comprensión propia de lo psíquico que poseería la primera, volvemos a encontrar el mismo problema: no se trata de un mero ejercicio de aplicación, ya que la propia escritura "tiende a disimular, en su seguridad, sus secretos de fabricación" (19), y no se la puede dar como una entidad reconocible de antemano frente a la cual disponer una matriz de lectura. Con ello, sin embargo, se haría justificada, en manos de la literatura, "la desaparición del psicoanálisis como un paradigma interpretativo" (Bayard 164; Rabaté 55). En cualquier caso, la dificultad para el psicoanálisis de escapar de su aspiración a imponerse en cuanto lectura es persistente.

\section{KAFKA Y EL SÍNTOMA}

A primera vista, con Kafka, pareciera que estamos ante el caso más emblemático de la construcción de un imaginario psico-familiar y edípico, donde todo parece fácilmente presto a la aplicación del psicoanálisis. "Los escenarios asfixiantes del Proceso y del Castillo, o las figuras entomológicas de la Metamorfosis hoy constituyen parte inevitable de nuestras representaciones del cuerpo (político o erótico) y de nuestras experiencias del poder equívoco de la figura paterna" (Pombo Nabais 159). Los análisis de Marthe Robert sobre Kafka son indispensables para comprender esta comunicación entre los escritos del checo y el corpus psicoanalítico. Al mismo tiempo, fueron 
decisivos a la hora de intentar una lectura ensayística que buscaba apoyarse de forma predominante en una lectura inmanente a los propios textos, atendiendo a cuestiones de naturaleza estilística y argumentativa.

En ese sentido, en lugar de tratarse de interpretaciones que echaran mano de recursos externos o trascendentes, Robert quiere enfocarse en el despliegue de los recursos escriturales. Antes que detenerse a descifrar las analogías entre el castillo kafkiano y, por ejemplo, el castillo del Graal, como se habría intentado leer, se interesará en "la crítica activa de los símbolos, metáforas, imágenes que acreditan en el espíritu de su héroe, así como a los ojos del lector y del crítico, la idea misma de que existe un castillo" (Robert, Kafka 101). Esta crítica supondría "deshacer pacientemente el trabajo secular de las palabras" (101), y, al mismo tiempo, permitiría describir un profundo realismo en la escritura de Kafka (Acerca de Kafka 25), que se basa en una abolición de la identidad, en una reducción del hombre a una simple expresión, "un hombre verdaderamente sin atributos en quien ya sólo sobrevive el último núcleo de lo humano" (Seul 12-13).

Lo que llama la atención es que dicho realismo profundo es lo que habilita a Robert a leer en Kafka una "disposición psíquica que le abocaba sin reservas al ensueño y le hacía vivir en cierta manera normalmente en una continua fantasmagoría" (Acerca de Kafka 25). Pero no hay aquí una lectura puramente causal que ligue unidireccionalmente esta disposición psíquica con sus escritos. La descomposición "paciente" de las palabras se alía con una concepción del arte más inspirada, como la misma Robert la denomina, produciendo un arte escritural basado en "una tentativa de autocuración mediante la representación activa de un conflicto" (Acerca de Kafka 31 n), que constituye "una paradoja insuperable":

Se trata también de una paradoja insuperable: para Kafka, la escritura es patológica en su base, y, sin embargo, está destinada a curar, a ser individual y socialmente útil. La enfermedad sigue siendo una enfermedad, pero al mismo tiempo es su remedio (Freud no dice otra cosa en su teoría de la 'sublimación') (31 n).

Esta mantención del conflicto es entonces la que permitirá la atribución de un carácter simbólico a la escritura de Kafka. Pero es un simbolismo muy especial, gatillado por el intento de resolver un compromiso psíquico. La mención a Freud hecha entre paréntesis nos permite entender que este simbolismo expresa un pharmakón: la escritura es patológica y, en esa medida, es tentativa de curación. El sentido de la sublimación es, precisamente, 
dar una salida a la mantención simultánea de ambos órdenes de realidad, producto de lo cual el mensaje simbólico "ya no es ambiguo, sino embrollado, intransmisible, debilitado en proporción idéntica a su confusión" (Acerca de Kafka 34). Incluso, en la misma línea, se podría decir que la escritura de Kafka -la exigencia de escribir- es "un medio de salvación psicológica (todavía no espiritual), un esfuerzo de una creación «que pueda ser ligado a su vida, palabra por palabra, que atrae hacia sí para que ella lo retire de sí mismo»" (Blanchot 58).

El carácter paradójico concedido a la sublimación nos pondría tras la pista de una conversión de la literatura que mantiene su rasgo patológico. Esa será la matriz que Robert sigue en el texto de Kafka y que, por la vía de este simbolismo, permite librarse del "delirio de interpretación" (Acerca de Kafka 34) que tomaría una clave de un terreno extraliterario, como código que nos permita descifrar el enigma oculto de una escritura. Aun cuando es cierto que en sus análisis se afirma la eficacia del simbolismo literario de Kafka - un simbolismo que, para Robert, es la clave de una producción de imágenes sin homólogos conocidos, que derrotan las comparaciones y metáforas comunes-, la lectura que hace desemboca en el señalamiento de que este simbolismo sería la cruz que cargan, como un poder contradictorio, los héroes de Kafka.

La pregunta es, a nuestro parecer, si con esta lectura la escritura literaria no termina por ser reducida al espacio de mantención de la salud psíquica que, en su precariedad, actúa como instancia trascendente que da una solución de continuidad a las brechas que el mismo texto de Kafka introduce. "La ley no deja a Kafka en paz [...] ella es la que se enuncia en La condena, mediante la voz terrible del padre-juez, a la vez grandiosa y senil; ella persigue a Joseph K. [...] Kafka muere por [...] esta ley inmanente que se enuncia en el automatismo del castigo [...], si es cierto, tal como está convencido, que la herida de sus pulmones no es más que el símbolo de otra llaga" (Seul 158-160). A fin de cuentas, Kafka está perdido, "salvo que la soberanía de decisión que le falta en la realidad de manera tan cruel, le sea restituida en el lugar lejano que es la literatura" (161).

\section{KAFKA, O LA LITERALIDAD DEL PSICOANÁLISIS}

El uso indirecto que hacía Robert de la sublimación freudiana en la lectura de Kafka terminaba por darle a la literatura la posición de un síntoma para lo 
que falta "en la realidad". La transición entre la vida psíquica y la literatura se haría, entonces, al precio de una continuidad explicativa que haría de la primera una instancia trascendente para dar sentido a la segunda. Ambas mantienen su distancia, pero al precio de la subordinación de una a la otra ¿Basta con traducir el conflicto escritural a una clave psíquica, y viceversa, manteniendo así una explicación en un dominio trascendente, reduciendo toda heterogeneidad? En principio, una vía sería poner en entredicho los elementos psico-biográficos para evitar asociarlos como significado trascendente de los textos. Ello, para dejar de considerar el elemento psicoanalítico como una mera instancia de contraste para los escritos de Kafka. Podemos recordar el juicio hecho por Walter Benjamin (1977) sobre las interpretaciones de los textos kafkianos. El error en el cual tradicionalmente incurren, tanto la interpretación natural como la sobrenatural, es que entorpecen el reconocimiento de que Kafka es un escritor que procede por unas parábolas muy singulares. Sin mayores explicaciones, Benjamin no duda en calificar la interpretación sobrenatural como teológica, y la natural, como psicoanalítica (425). Las parábolas de Kafka se resisten a ser tomadas por sí mismas, en su sentido común, y ello porque no encuentran la doctrina a la cual remitirían para ser completamente inteligibles. Lo máximo que podemos decir sobre esta doctrina inencontrable es "que este o aquel fragmento aluden a ella" (421), y que, en la medida en que "toda la obra de Kafka representa un código de gestos que no poseen un significado simbólico inherente para el autor" (418), es la misma doctrina la que titubea en ofrecerse como clave de lectura con un sentido propio.

Podríamos conjeturar que lo que Benjamin denomina "interpretación psicoanalítica" obedece a la doctrina que aplicaría directamente un corpus de saber sobre la vida psíquica y sus conflictos para constituirse en clave de los escritos. Al hacer eso, se pasaría por alto el bloqueo mismo en el acceso, que es lo decisivo de la parábola pensada por Benjamin. Adorno seguirá la misma línea, y afinará ese énfasis sobre la escritura de Kafka, precisamente al momento de apelar a un contraste con una lectura hecha desde el psicoanálisis. Según su lectura, lo que fascina de Kafka es la inexistencia de una fusión entre la literalidad y el significado de una frase. Primero genera un sentimiento de familiaridad, pero hace fracasar el camino hacia el significado al cual remite dicho sentimiento. "Cada frase dice: «Interprétame» [deute], y ninguna lo tolera. Con la reacción «Así es» cada frase obliga a preguntar: «¿De qué lo conozco?»; el déjà $v u$ se declara permanentemente. Mediante la violencia con que obliga a interpretar [Deutung], Kafka traza la distancia estética" (Adorno 249-250). 
Habría una literalidad en Kafka -un principio de literalidad, Wörtlichkeitque hace que "las palabras, especialmente las metáforas, se liberen y ganen su existencia propia" (251). Esta literalidad sería lo que tendría que impedir que la mera arbitrariedad interpretativa se impusiera como un significado trascendente al texto, bajo los visos de una pretendida profundidad. Adorno formula incluso la siguiente sentencia para los escritos de Kafka: "Tomar todo literalmente, no tapar nada desde arriba con conceptos" (251). Nos detenemos en esta literalidad ya que pareciera ser lo que se opone abiertamente a una lectura psicoanalítica. Freud y Kafka aparecen puestos uno frente al otro, uno como "investigador de lo inconsciente" y el otro, en tanto "parabolista de la impenetrabilidad", respectivamente. ¿Es que acaso la lectura psicoanalítica "tapa desde arriba con conceptos”? ¿El investigador de lo inconsciente iría tras significados, mientras el parabolista de la impenetrabilidad no le quedaría más que mantenerse a distancia de ellos, solo provisto de los fragmentos de una doctrina fugada para siempre? Así pareciera ser, ya que Kafka sería todavía mucho más escéptico que Freud respecto a la función del yo, que en el primero pareciera suspenderse en beneficio de una "literalidad [Buchstäblichkeit]" que procede como un "diseño experimental [Versuchsanordnung], [donde se] estudia lo que sucedería si los hallazgos del psicoanálisis no se aplicaran solo metafórica y mentalmente, sino corporalmente" (256).

Kafka pareciera dar un paso más allá al tomar al psicoanálisis más literalmente. El "parabolista de la impenetrabilidad" procede literalmente, proporcionando una medida para lo plurívoco, con el objeto de impedir que ello sea lo puramente arbitrario que se pretende como profundo (252). Para Adorno, este apego a la letra -y a la letra en la palabra- proyectaría un futuro en los escritos de Kafka, que actúa a expensas de un sujeto:

En lugar de curar la neurosis, [Kafka] busca en ella la fuerza curativa, la fuerza del conocimiento: las heridas que la sociedad imprime al individuo son leídas por éste como cifras de la falsedad social, como el negativo de la verdad. La fuerza de Kafka es la fuerza de la demolición $[A b b a u]$. Derriba la tranquilizadora fachada que oculta la desmesura del sufrimiento y a la que el control racional se adecúa cada vez más. Al demoler [...], Kafka no se detiene en el sujeto, como haría la psicología, sino que penetra en lo material, en lo meramente existente, que se ofrece en la caída al fondo subjetivo de la consciencia que renuncia la autoafirmación. La fuga $[$ Flucht $]$ a través del ser humano hacia lo no humano es la vía épica de Kafka (256-257). 
Adorno ha leído a Kafka como quien "encontró palabras para el espacio de la interioridad sin objeto". Para ello, Kafka ha tenido que comportarse como Utrillo, quien se basó aparentemente en tarjetas postales para pintar sus heladas calles. La demolición del sujeto, que hace fugar el elemento humano, nos muestra un paisaje no unificado, en que la mirada del escritor, luego de retirar todas las investiduras afectivas de los objetos, "los petrifica y los convierte en algo que no es ni un sueño (que puede ser falsificado), ni una imitación de la realidad, sino su imagen enigmática, formada a partir de sus trozos dispersos [zerstreuten Bruchstücken]" (272). Esa descripción -ese trabajo descriptivo- nos permitirá adelantar el elemento de la dispersión que dibuja el relato kafkiano, que es precisamente el terreno donde se puede elaborar, a nuestro juicio, una lectura más singular de la mano del psicoanálisis.

\section{UNA TRASCENDENCIA EN LAS BRECHAS DEL TEXTO}

"Kafka's Voices", de Mladen Dolar, toma varios de los relatos de Kafka para tratar de sortear el atolladero que se produce entre las lecturas trascendentes y las inmanentes que se hacen de ellos. Una lectura trascendente -por ejemplo, podría ser el caso de Marthe Robert, o de aquello que Adorno y Benjamin han reconocido en el psicoanálisis- buscaría el sentido de un texto en algún punto delimitado exteriormente a este, mientras que una inmanente lectura trataría de leerlo para recorrer sus operaciones progresivas de despliegue (y a este respecto, Dolar remite al único caso de la lectura hecha por Deleuze y Guattari en 1975). Podríamos pensar que se trata de una manera de proporcionar un esquema de gran alcance, pero la distinción no quita dificultad al hecho de que ambas lecturas tomen como referencia el peso de la ley que se expone, de diversas formas, en los escritos de Kafka. Dolar afirma que sin duda la lectura inmanente -donde uno está atrapado en la inmanencia de la ley-es mucho más útil y tiende menos a los malentendidos que una trascendente, pero seguiría sin cubrir lo que está en juego en el caso de Kafka. La lectura de tipo inmanente, "al promover la dimensión de la pura inmanencia, quizá elude, reduce y evita una paradoja: la paradoja de una emergencia de una trascendencia en el corazón mismo de la inmanencia" (313).

Por el momento mantendremos en reserva qué implica contraponer aquí una "pura inmanencia" a una "trascendencia en el corazón mismo de la inmanencia". En Vor dem Gesetz (Ante la ley), cuando el campesino pregunta al guardián sobre la posibilidad de cruzar la puerta que lo separa de la ley, este último le 
responde: "es posible [möglich] pasar, pero no por ahora [jetzt aber nicht]" (Kafka, Erzählungen 201). En el momento en que el campesino confirma que el acceso era solo para él, la puerta se cierra. Como lo ha advertido de un modo muy acertado Werner Hamacher, la relación con la ley sería una relación con el "Ante" (Vor) de la ley, con la estructura preposicional de dicho "Ante" (360). Como veremos, las preposiciones tendrán una importancia específica en Kafka, manteniendo una contigüidad que aplaza eso mismo que se enuncia afirmativamente. En este caso, el propuesto por Hamacher, la ley misma mantiene interminablemente su aperturidad, es "impenetrable, invisitable, invisible" (360).

En Kafka, las leyes se presentan incluso como todavía desconocidas y solo como materia de adivinación. De hecho, se requiere que la existencia de estas leyes se mantenga en secreto (Geheimhalten) (Beschreibung 68-69). Los símiles fracasan, porque en el intento de pasar por la puerta de la ley -y esperando encontrar algo que ver- somos nuevamente devueltos hacia otra cosa que la trascendencia. No experimentamos la falta de trascendencia que resurge en ese "Ante" la ley, sino que al enterarnos de la trascendencia que no alcanzamos de ese "otro lado" nos devuelve a la experiencia de lo ininteligible.

Cuando el sabio dice: "Ve hacia allá", no quiere decir que uno deba pasar al otro lado [andere Seite], que siempre sería posible si la meta así lo justificase, sino que se refiere a otro lado mítico [sagenhaftes Drüben], algo que nos es desconocido, que tampoco puede ser precisado por él con mayor exactitud y que, por tanto, de nada puede servirnos aquí. En realidad, todas esas alegorías [Gleichnisse] sólo quieren significar que lo ininteligible [das Unfaßbare] es ininteligible, lo que ya sabíamos (72).

Lo que aquí nos interesa destacar es que esta dificultad de discernir entre un interior y un exterior no se limita a declarar inaccesible a la ley como algo trascendente, sino que viene a marcar la existencia de una "exterioridad absoluta, [un] exilio de la ley desde la ley" (Hamacher 361). De hecho, "es la aperturidad de la ley que se sustrae a la oposición entre afuera y adentro, es su aperturidad misma la que se cierra. Ley es que siempre solo haya un Ante la ley" (360). Podríamos decir, que la ley no coincide consigo misma, y que oponerle algo sería descubrir sobre todo esa discordancia. ¿Pero basta con pensar esta discordia de la ley como un momento de trascendencia en el corazón de la inmanencia, que echaría por tierra las lecturas que enfatizan 
una "pura inmanencia"? Es una pregunta que persiste, dado que todavía es posible que lo que se denomina así no sea "puro" en el sentido de estar liberado de sus propios intervalos y pliegues.

Sin embargo, es preciso seguir lo que dice Dolar en su argumento, ya que también parece apuntar a enfatizar esa falta de pureza. Para él, el problema que arrastran las lecturas inmanentes es "la manera en que la inmanencia siempre se dobla e intersecta consigo misma. $\mathrm{O}$, para decirlo de otro modo: podría no haber interior, podría no haber exterior, pero el problema de la intersección permanece" (313). Evidentemente, siguiendo la estela de la última enseñanza de Lacan, se está anticipando aquí un modelo topológico, "en el que la curvatura del espacio establecería un vínculo entre el interior y el exterior" (313). Incluso hace una rápida mención a la sesión del seminario del 21 de marzo de 1962, de Lacan, donde el relato tardío Der Bau (La construcción), de Kafka, será "una analogía irreductible" para dar cuenta de cómo el interior y el exterior se interpenetran y comandan mutuamente, y cómo dicha distinción se impone brutalmente para el sujeto. Sin embargo, como intentaremos mostrar a continuación, afirmar una lectura inmanente -incluso una de "pura inmanencia"- no implica en modo alguno afirmar una interioridad en detrimento de la exterioridad.

Tenemos que notar que Dolar lee a Kafka para mostrar que la intersección en sus relatos equivaldría a reintroducir la trascendencia en la inmanencia. No podemos perder de vista que no se trata simplemente de oponer ni disolver lo exterior y lo interior, sino de mantenerse en el entrecruce de ambos para tratar de salir del encierro de la ley en los textos kafkianos. La voz se ofrecería, para Dolar, como la via regia para salir de la pura inmanencia, ya que permitiría pensar el problema de la intersección. Apegado a las enseñanzas del psicoanálisis lacaniano, sostiene que la voz permite pensar más allá del significado y, por consiguiente, "está estructuralmente situada en el punto de excepción de la ley" (316). Como lugar de paso entre cuerpo y significante, la voz sería el repliegue en el espacio curvo, la intersección que prueba la incapacidad de sostener una pura inmanencia.

Tomando tres relatos de Kafka, Dolar buscará mostrar que el tratamiento de la voz es el que mejor exhibe la salida. Primero, la trasformación de Gregor Samsa en Die Verwandlung (La metamorfosis) significa "la salida de todos los papeles simbólicos que había asumido; su condición de insecto [insecthood] es al mismo tiempo su liberación" (321). Pero inmediatamente la metamorfosis viene a representar un intento, fallido, de escapatoria: aquella todavía es la prueba más dramática de lo que la ley ha hecho de los 
sujetos, insectos. Ello no impide, sin embargo, que Samsa haga tambalear el presupuesto implícito de la ley, ya que "destruye la metáfora al tomársela literalmente, al literalizarla; así, la metáfora se desmorona, la distancia de la analogía se evapora y la palabra se convierte en la cosa" (321).

En segundo lugar, Josefina, en Josephine die Sängerin oder das Volk der Mäuse (Josefina la cantora, o el pueblo de los ratones), el último relato escrito por Kafka (marzo 1924), hace aparecer una voz indistinguible de la voz de la ley, pero heterogénea a ella. Josefina no canta, solo hace algo como un silbido (Kafka, Erzhälungen 201), pero de grandes efectos. Un silbar pequeñísimo, que "se libera de las ataduras de la vida cotidiana" (210), y que en su caso introduce una brecha en la ley ("la imperceptible grieta que la separa de todas las demás voces sin dejar de ser absolutamente lo mismo, una mera nada en la voz", 322). Ese silbido o chillido que acompaña a la voz declararía una "repentina intrusión de la trascendencia en la inmanencia, pero una trascendencia que se queda en medio mismo de la inmanencia y parece exactamente lo mismo, la diferencia imperceptible en la misma mismidad" (322). Pareciera que no se puede estar ni fuera ni dentro de la ley, lo que se traduce como: no se puede estar sobre ella, pero tampoco ser uno con ella. En dicho movimiento, su voz introduce "una brecha en la continuidad como la trascendencia en la inmanencia" (335 n). Pero es el arte de Josefina lo que pareciera traicionar su tentativa, al convertir a la grieta en institución de la grieta, y así, al circunscribir su lugar de excepción, se ajusta a la norma de la ley. "Su voz, que abre la grieta en la continuidad sin fisuras de la ley, es traicionada y destruida por el estatus mismo del arte, que la reinserta y cierra la brecha" (324).

La trascendencia que prometía termina por devolverse contra Josefina: su arte, que prometía esa trascendencia, permite que la brecha vuelva a encajar demasiado bien en la continuidad (325). Dolar recurre entonces a una lectura final, las Forschungen eines Hundes (Investigaciones de un perro), para responder a la posibilidad de salir de la inmanencia. En este relato póstumo, el perro-narrador nos cuenta un quiebre en su vida: un día, el pequeño perro que es hoy el obsesionado narrador de sus investigaciones, asistió sin quererlo a una suerte de escena primordial donde otros perros ya adultos se encontraban reunidos alrededor de su propia música. Ellos, "no hablaban, no cantaban, en general se mantenían casi en silencio con gran tenacidad, pero como por encanto hacían brotar la música del espacio vacío" (Kafka, Beschreibung 183). En esa escena todo era música, todos los movimientos, y Kafka describe los aprendizajes conjuntos de los perros a la vista de este joven perro narrador. 
Sonido mudo, pero no silencioso, que provenía inalterable de la lejanía, pero que el joven perro experimenta como un silencio que se sufre y que es "lo único con que se me responde por doquier".

Para el narrador, ese quiebre sucede muy pronto: "me privó de gran parte de mi infancia". Pero, como él mismo nos dice, "hay cosas más importantes que la infancia. Y tal vez en la vejez, trabajado a través de una vida dura, habrá más felicidad infantil de la que un niño de verdad tendría la fuerza para soportar, que entonces tendré" (187). En la interpretación de Dolar, la voz del perro-investigador no es otra que la del psicoanálisis:

Hay cosas más importantes que la infancia: esto debería verse también como el eslogan del psicoanálisis, todo el cual parece tratar de la recuperación de la infancia, pero no para conservar esta cosa preciosa y única, sino para abandonarla. El psicoanálisis está del lado del perro joven que decide crecer, dejar atrás la "dichosa vida de un perro joven", comenzar sus investigaciones, ponerse a indagar, emprender una búsqueda (Dolar 328).

Por ello, al cerrar el análisis, y precisamente cuando se cierra el relato, Dolar no deja de enfatizar la mención a la libertad que en él se hace. La libertad, Freiheit, que el narrador aprecia a partir de su actividad investigadora, libertad que es "una planta enclenque" (215), pero un bien, al fin y al cabo. Esa libertad sería emparentada por Dolar con una "línea de fuga", esa libertad cuya ciencia sería el psicoanálisis (333). Pero habría que leer esta apelación final a la libertad de la mano con los pasajes de Ein Bericht für eine Akademie (Informe para una academia), donde se trata de la salida, Ausweg, y donde precisamente es contrapuesta a la libertad:

No me refiero a esa gran sensación de libertad por todos lados. Como mono, puede que lo haya sabido y he conocido a personas que lo anhelan. En cuanto a mí, sin embargo, no pedí libertad ni entonces ni ahora. Por cierto: con la libertad uno engaña con demasiada frecuencia a la gente. Y así como la libertad es uno de los sentimientos más sublimes, también lo es el engaño correspondiente entre los más sublimes. [...] No, no quería libertad. Solo una salida; derecha, izquierda, donde sea; No hice otras demandas; la salida debería ser incluso una ilusión; la demanda era pequeña, el engaño no sería mayor. ¡Adelante, adelante! Simplemente no te quedes quieto con los brazos en alto, presionados contra la pared de una caja (Kafka, Erzählungen 142). 
Esta preocupación por la salida será, a nuestro juicio, lo que terminará por desordenar a las lecturas psicoanalíticas, tanto aquellas centradas en el significado oculto en los textos de Kafka, como aquellas -el caso de Dolar es aquí nuestro ejemplo-que se centran en elementos del corpus psicoanalítico para leerlos en la relación que los escritos kafkianos mantienen con la ley y el deseo.

\section{NEBENZIMMER, O EL LABERINTO DE LA CONTIGÜIDAD}

El Kafka, de Deleuze y Guattari, supone una confrontación abierta con las lecturas psicoanalíticas, no solo con aquellas que habrían tratado de imponer un significado trascendente al texto, sino también con aquellas que quisieran leer el laberinto del deseo y de la ley enquistado en el texto mismo. Se interrogan por la situación de la ley en los textos de Kafka, advirtiendo que el hecho de que ella se mantenga incognoscible no se debe a que ella se encuentre "retirada en su trascendencia [...] sino simplemente [al hecho de que] ella está desprovista de toda interioridad" (Kafka 82). Esta ley, en tanto "pura forma de exterioridad", permite escapar de las interpretaciones que visualizan a un Kafka cuya enunciación se hace siempre desde la imposibilidad producida por la coerción de una ley inalcanzable y despiadada. De ahí que el motivo no sea el de la libertad, sino el de la salida y, por consiguiente, el de la entrada. Para los autores, una entrada siempre está constituida por su potencia de conexión con otras cosas que vendrán (8).

Ello implica todo un "método" de lectura:

Entraremos por cualquier extremo, ninguno vale más que otro, ninguna entrada tiene privilegio, incluso si es un callejón sin salida, un túnel estrecho, un sifón, etc. Sólo buscaremos con qué otros puntos se conecta aquel por el cual entramos, por cuales encrucijadas y galerías pasamos para conectar dos puntos, cuál es el mapa del rizoma, y cómo ese mapa se modificaría inmediatamente si se entrara por otro punto. El principio de las entradas múltiples sólo impide la introducción del enemigo, el Significante, y los intentos por interpretar una obra que de hecho sólo se propone a la experimentación (7).

Se entiende, entonces, por qué sería más importante una simple salida, “a derecha, a izquierda, a donde fuera", lo menos significante posible” (13), ya que la libertad todavía se mediría con la sumisión y estaría comprometido con 
ella. Por eso, el léxico mismo cambia: "El problema no es en lo absoluto ser libre, sino encontrar una salida, o bien una entrada, o un costado, un pasillo, una adyacencia, etc." (15). Si lo decimos de un modo muy rápido e impreciso todavía: la libertad sería un asunto de trascendencia, mientras que la salida marcaría otra relación con la ley. Todo lo que ocurre lo hace en la oficina de al lado, detrás de la puerta, en la habitación vecina; más que depender de la orden dada desde el principio de la cadena de mando, es la contigüidad de ciertos desplazamientos lo que da continuidad al proceso.

En varios de los escritos de Kafka hay toda una obsesión por el tema de la contigüidad, que incluso valdría eventualmente para ser extendido mucho más de lo que aparece explícitamente. Se puede empezar por Die Verwandlung, donde todo el relato ocurre con atención a la habitación adyacente. Más importante que su transformación, nos parecen los momentos en los cuales su padre le habla desde la habitación contigua, sin todavía abrir la puerta (Kafka, Erzählungen 63), no tanto para que no se lo vea como para que no se lo escuche. Las descripciones se hacen desde una habitación a otra, de una a la del costado. "En la habitación contigua a la izquierda hubo un silencio vergonzoso, en la habitación contigua a la derecha la hermana comenzó a sollozar" (64). Neben es una preposición que, en este caso, señala la adyacencia y el estar-junto-a. Todo el intercambio con la hermana, la madre, y luego su padre y el apoderado que llega desde la empresa en la cual trabaja, se llevan a cabo entre habitaciones adyacentes unas a otras, y parece remarcar el hecho de que lo que está sucediendo a Gregor -y lo que él mismo es- está perpetuamente implicado en algo otro.

Gregor se apega a la habitación contigua, pero todo parecía indicar que no podía pasar, al menos no de un modo simple. Todos los movimientos parecen darse in situ, pero sin plena coincidencia consigo mismos. De una habitación a otra, él se mantiene silencioso, para evitar que los sonidos que emite suenen diferente a una voz humana, tal como sucede con su tos. Hay que recordar que se sorprende al escuchar su voz, "inequívocamente su voz anterior", pero donde ahora se venía a mezclar "un pitido doloroso que no podía ser reprimido, que formalmente hacía claras las palabras, pero solo durante un primer momento. Después de ello las destruía, de modo tal que uno no supiera si había escuchado correctamente" (59).

Que todo ocurra al lado, en la habitación contigua, es algo que ya Deleuze y Guattari habían advertido en toda su extensión y enfatizado en el procedimiento kafkiano. ¿Por qué todo ocurre al lado? Primero, porque el deseo que moviliza los relatos se moviliza de salto en salto, sin proceder a 
la siga de un objeto -por mucho que este esté perdido de antemano-, sino mediante una no-unificación de los tramos que recorre. Esta contigüidad es una manera de escapar de "la jerarquía de las instancias y de la eminencia del soberano" (Deleuze y Guattari 92) y ella, al contrario de la infinitud de una trascendencia, requiere ser pensada como "un campo ilimitado de inmanencia" (93). Esto hace que el proceso del deseo sea un continuo, pero uno que no se opone a lo contiguo, sino al contrario. Lo contiguo es, respecto a lo continuo, "su construcción local, indefinidamente prolongable, y por lo tanto su desmontaje - siempre la oficina de al lado, la habitación contigua" (94). Pareciera que el continuo se extrae de la prolongación indefinida de lo contiguo. Sin embargo, lo contiguo es también el desmontaje de lo continuo: lo que sucede siempre lo hace en la oficina de al lado. El continuo se descalza en la construcción local. Esto quedará más claro cuando el campo de lo continuo sea caracterizado como una "prórroga ilimitada". K no quiere ser absuelto aparentemente de su culpabilidad, pero no porque espere la absolución real. La absolución aparente todavía lo ata a la trascendencia; se promete su absolución, y esta actúa como razón extrínseca que direcciona los diques que sigue el deseo.

Es por esta razón que Deleuze y Guattari pueden decir que la absolución es "infinita y limitada, discontinua" (95), manteniendo a la ley en su trascendencia. A una circulación de las piezas, le aleja el punto de acusación, valiéndose de oposiciones (por ejemplo, entre libertad y sometimiento). Sin embargo, la prórroga es "finita, ilimitada y continua": finita porque no hay trascendencia y se opera por segmentos, localmente; ilimitada y continua, "porque no deja de agregar un segmento a otro, en contacto con otro, contiguo al otro, que opera pedazo a pedazo para aplazar siempre el límite" (95).

En este sentido, la polémica contra el criterio trascendente de lectura, es porque ella implica la reducción del deseo. Se trata más bien de una coexistencia entre dos estados de movimiento, dos estados de deseo o dos estados de ley, y que darían razón de la ausencia de un criterio trascendente. Así, lo contiguo es "en sí mismo una línea de fuga activa y continua" (111). La señal de una coexistencia entre dos estados, el hecho de que cada uno, desde su punto de vista en tal o cual segmento, está en contacto y en contigüidad con el proceso "como potencia ilimitada del continuo" (116). Por eso, la contigüidad no puede ser simplemente discontinua: solo la trascendencia está exteriormente limitada, porque reparte los puntos de detención y los vacíos intervalares entre los estados. La discontinuidad todavía sería la huella de una máquina trascendente y retirada. Para Kafka, de hecho, "lo inacabado ya no es lo fragmentario, sino lo ilimitado" (132). En términos de Deleuze y 
Guattari, Kafka no procedería por lo infinito-limitado-discontinuo, sino por lo finito-contiguo-continuo-ilimitado.

El método que Deleuze y Guattari presentan hace proliferar y acelera los segmentos, para conjugar lo finito y lo ilimitado, lo continuo y lo contiguo (108). Este método conecta los bloques de contigüidad para una línea continua ilimitada. En dicha línea, los segmentos definidos por las habitaciones se mantienen contiguos entre sí, pese a estar muy lejos. Gregor nunca termina de acercarse y coincidir con quienes interactúa, principalmente su familia. De este modo, la distancia puede ser cercana, y lo continuo puede ser lejano. Lo contiguo no es cercano, sino que las conexiones se llevan a cabo entre habitaciones y movimientos que no terminan de alejarse unos de otros, que nunca terminarán de reunirse en una habitación central.

La distancia, que remite al mantener dos cosas separadas, es aquí descartada porque parece indicar una separación discernible, que así constituiría dos entidades con límites enteramente definidos y sin posibilidad, creemos, de implicación y compenetración. Es así como Deleuze y Guattari pueden describir que "lo contiguo y lo lejano forman parte de otra dimensión, la longitud, la línea recta rectilínea, transversal a la trayectoria del movimiento, y que vuelve contiguos los segmentos más lejanos" (138). Estos segmentos, al hacerse contiguos, "pierden sus límites precisos, en beneficio de barreras móviles que se desplazan y se precipitan con ellos en la segmentación continua" (140). El carácter serial de dicha segmentaridad permite precipitar la contigüidad en una segmentación continua, lo que permite decir, por ejemplo, que el padre y la madre de Gregor son "cercanos y distantes" (en tanto son emanaciones de la ley), mientras que su hermana (a quien busca reiteradamente para poder deleitarse escuchando tocar su violín, desde la habitación de al lado) no es cercana, "ella es contigua, contigua y lejana" (138-139).

En Der Bau, el narrador -presuponemos que se trata de un topo- nos describe los pormenores de la construcción de su madriguera, un intricado sistema de túneles y pasajes subterráneos que comunican el interior con el exterior. Una de las primeras cosas que nos cuenta es la importancia que tiene para él ser consciente de que en alguna parte de su construcción hay una salida expedita. Los laberintos de la construcción instan a que el narrador se pierda a sí mismo, donde "solo hace falta un movimiento de cabeza y estoy en un lugar extraño" (140). Todo el relato da cuenta de la tranquilidad hogareña que siente el narrador en su madriguera, que no deja de coexistir con un perpetuo repaso a los distintos habitáculos y pasajes, y a las pequeñas modificaciones que no dejarían de hacerse para trazar los movimientos en 
ella. Esa madriguera bien podría ser la fórmula misma de cómo tendríamos que comprender el carácter laberíntico del deseo, y cómo va juntando una a una sus piezas en la escritura de Kafka.

En un bello ensayo reciente sobre Kafka, Joseph Vogl ha advertido que los textos del checo funcionan con umbrales [Schwellen], como momentos de paso elementales en un espacio topológico.

El espacio de umbral transicional de Kafka contiene la instrucción para la producción de lo que podría llamarse Atopos: ni un lugar específico ni un no-lugar, sino un lugar degenerado, una situación espacial que hace que cada lugar en particular se tambalee y se deslice. El espacio no tiene suelo o fundamento sólido y desconoce las inscripciones de orden y orientación (Vogl 84).

Vogl nos da entonces una pista respecto al espacio que bosquejan los textos de Kafka. Es un extraño espacio, inextenso o pre-extenso, que se organiza desde el spatium, el intervalo. Antes que tratarse de meras brechas, las interrupciones de la extensión espacial alteran las coordenadas y orientaciones, mostrando "un espacio en estado incompleto, un espacio embrionario que consiste en el 'entre', de posiciones y lugares desconectados. No tiene fronteras ni horizonte, ni interior ni amplitud y, sus aberturas solo incluyen más recintos" (84). Este espacio no homogéneo es, literalmente, laberíntico. El laberinto es una línea, una línea continua -como en el laberinto del continuum definido por Leibniz en el siglo XVII-, que puede detenerse en cada uno de sus puntos y cambiar de dirección, ramificándose y volviéndose discontinua.

En el espacio de dicho laberinto, "cada lugar puede hacer referencia virtualmente a cualquier otro lugar, sin transiciones". Es un espacio definido por "un conjunto de singularidades inconexas, de relaciones virtuales", por "un proceso de interpolación infinito, un arbitrario conjunto de intervalos en un continuum" (89), que mantiene un inexpugnable carácter diferencial, pero desplegados en "una especie de ocupación continua [Dauerbeschäftigung] con cualquier intervalo arbitrario, por pequeño que sea" (89). Es esta extraña coexistencia entre continuidad y arbitrariedad lo que impide oponer lo continuo a lo contiguo, y la pura inmanencia al intervalo. De hecho, es este último lo que requiere que la línea laberíntica tenga que ser pensada en sus complicaciones, pero sin que estas nos habiliten a introducir una trascendencia ni apelar a la libertad. Si el psicoanálisis guarda relación con alguna libertad, ello no nos permitirá ver lo que se abre en intervalos que no dependen de esa todavía "planta enclenque", como decía el perro-investigador. 
Ahora bien, tendríamos que entender esta línea laberíntica rigurosamente al pie de la letra en el texto kafkiano. Es ella la que promueve una nueva conexión para elementos que antes parecían soldados por su uso, constituyendo significados inamovibles. La literalidad es esa pura potencia conectiva (Zourabichvili 42), según la cual se conjugan dos series, sin que una sirva de base a la otra, como podía ocurrir en el caso de la vida psíquica para ordenar la escritura literaria. En este sentido es que, si la literatura kafkiana es un laberinto, es primero una línea "que 'yerra' en todos sus puntos, ramificándose e interrumpiendo la continuidad de su trayecto, demorando continuamente su camino" (90). La línea se va haciendo al divergir en distintos puntos de quiebre, donde remonta y se retoma, pero en su pura diferencia. La pura inmanencia no sería otra cosa que eso: el deseo se persigue a sí mismo en el texto kafkiano, pero sin subordinarse ni subsumirse. Más bien, vacilando: así Vogl entiende el laberinto que producen los escritos de Kafka, laberinto que no indica un camino propiamente, solo una vacilación [Zögern] (93), que va trazando un "camino continuamente demorado [gezaudert]" (91).

La habitación contigua, la salida que se busca interminablemente pero que aplaza el hecho de encontrarse en una estancia, marcarían un procedimiento de demora [Zauder-Verfahren], que abre paso a un mundo emergente [Schwellenwelt], un mundo de umbrales (104), que va conectándose salto a salto, sin reunirse en una unidad. Si la contigüidad del deseo tendría que mantener toda la diferencia en sus segmentos, toda la diferencia en sus propias dimensiones, ello es porque las brechas son la parte más concentrada del continuo y el punto de aproximación de segmentos diferentes. A propósito de Proust, Deleuze ha podido decir que con esas junturas se va trazando una transversal que, lejos de reunir un continuo homogéneo (o una "pura inmanencia sin trascendencia"), pone una parte junto a otra, siempre agregando una vista adyacente que no termina de cerrar la potencia conectiva, y que aparece siempre como contiguo a lo que se está viendo, haciendo imposible saturar un punto de unidad (193).

Precisamente por lo anterior se haría imposible entender la libertad como una "línea de fuga" como lo pensaba Dolar. Ni Gregor Samsa ni el topo, ni el simio del Informe luchan por la libertad o son movilizados por ella. No buscan una salida para ser libres, y el deseo que ellos exponen no necesariamente implica alguna constatación del ejercicio de la ley. Es también en este sentido, que Deleuze y Guattari advierten que en Kafka el problema del padre no es forzosamente edípico: la cuestión no es "cómo volverse libre con relación a él (...), sino cómo encontrar un camino donde él no lo 
encontró" (19). Pese a ello, siempre se puede diagnosticar al texto kafkiano, siempre se lo puede hacer por parte de un orden que quiere hacerlo hablar el habla de algún padre, el habla familiar. "Uno se hace re-edipizar, pero no por culpabilidad, sino por cansancio, por falta de invención, por imprudencia de lo que desencadenó..." (Deleuze y Parnet 59-60). Pero buscar salidas es experimentar y no saber hacia dónde se va, ni de dónde se viene. Es ganarle al cansancio de la detención sumisa, para agotar las posibilidades que cansan.

Quizá Kafka habrá sido el agotado, del cual habla Deleuze a propósito de Beckett. El mundo emergente, hecho de umbrales que componían el continuo haciendo saltar su pura homogeneidad, que Vogl nos presentaba, es un mundo donde "se combina el conjunto de variables de una situación, con la condición de renunciar a todo orden de preferencia y a toda organización de objetivos, a todo significado. (...) Ya no se realiza, por más que se efectúe. (...) Uno no cae por ello en lo indiferenciado, o en la famosa unidad de los contrarios, y no se es pasivo: uno se activa, pero para nada" (Deleuze, "L'épuisé" 59-60). Nada posible que ya haya estado prefigurado, y que nos permita detenernos, descansar en él. Una salida puede permutarse por otra. Extrañamente, agotar lo posible es combinar más salidas, incluso aquellas que no pueden estar todavía delineadas. "Pero sólo el agotado puede agotar lo posible, porque ha renunciado a toda necesidad, preferencia, objetivo o significado. Sólo el agotado es lo bastante desinteresado, lo bastante escrupuloso. Se ve forzado a reemplazar los proyectos por tablas y programas desprovistos de sentido" (61).

Quizá los textos de Kafka no sean otra cosa que el testimonio de seguir el deseo, donde saltos y cortes van distribuyendo una línea continua, y lo hacen siempre con grados de inclinación y divergencia que ninguna orientación hacia la libertad podría seguir. Porque el deseo no conoce la libertad y es posible que no esté ocupado de ella, sino tan solo en afirmar su propia potencia conectiva.

\section{BIBLIOGRAFÍA}

Adorno, Theodor W. "Aufzeichnungen zu Kafka”. Prismen. Kulturkritik und Gesellschaft. München: Deutscher Taschenbuch Verlag, 1963. 248-280.

Bayard, Pierre. Peut-on appliquer la littérature à la psychanalyse? Paris: Minuit, 2004.

Benjamin, Walter. "Franz Kafka. Zur zehnten Wiederkehr seines Todestages". Gesammelte Schriften. Zweiter Band, Zweiter Teil. Frankfurt: Suhrkamp Verlag, 1977. 409-438.

Biswas, Santanu. "A literary Introduction to 'Lituraterre"”. The Literary Lacan. From Literature to Lituraterre and Beyond. Ed. Santanu Biswas. London: Seagull Books, 2012. 173-195. Blanchot, Maurice. L'espace littéraire. Paris: Gallimard, 1955. 
Deleuze, Gilles. Présentation de Sacher-Masoch. Le froid et le cruel. Paris: Minuit, 1967. Proust et les signes. Paris: Presses Universitaires de France, 1970. “L'épuisé”. Samuel Beckett. Quad et autres textes. Paris: Minuit, 1992.

Deleuze, Gilles y Claire Parnet. Dialogues. Paris: Flammarion, 1977.

Deleuze, Gilles y Félix Guattari. Kafka. Pour une littérature mineure. Paris: Minuit, 1975.

Dolar, Mladen. “Kafka's voices”. Lacan. The Silent Partners. Ed. Slavoj Žižek. London/New York: Verso, 2006. 312-335.

Felman, Shoshana. "The Case of Poe: Applications/Implications of Psychoanalysis". Essential Papers on Literature and Psychoanalysis. New York: New York University Press, 2003. 300-322.

Freud, S. "Das Interesse an der Psychoanalyse". Gesammelte Werke, VIII. Werke aus den Jahren 1909-1913. London: Imago Publishing, 1948. 389-420.

Freud, Sigmund y C. G. Jung. The Freud/Jung Letters. Ed. William McGuire. Princeton: Princeton University Press, 1974.

Hamacher, Werner. "El gesto en el nombre. Benjamin y Kafka", Comprender detraído. Estudios acerca de filosofía y literatura, de Kant a Celan. Trad. Niklas Bornhauser. Santiago: Metales Pesados, 2018. 353-401.

Kafka, Franz. Gesammelte Werke IV, Erzählungen. Frankfurt: Fischer Verlag, 1976a.

Gesammelte Werke V, Beschreibung eines Kampfes. Novellen, Skizzen, Aphorismen. Aus dem Nachlaß. Frankfurt: Fischer Verlag, 1976b.

Kofman, Sarah. L'Enfance de l'art. Une interprétation de l'esthétique freudienne. Paris: Galilée, 1985.

Lacan, Jacques. "Lituraterre". Autres écrits. Paris: Seuil, 2001. 11-20.

Pombo Nabais, Catarina. Gilles Deleuze: philosophie et littérature. Paris: L'Harmattan, 2013.

Rabaté, Jean-Michel. "Psychoanalysis Applicable and Inapplicable: The Case of Literature". The Literary Lacan. From Literature to Lituraterre and Beyond. Ed. Santanu Biswas. London: Seagull Books, 2012. 51-85.

Robert, Marthe. Kafka. Trad. Carlos A. Fayard. Barcelona: Paidós, 1969. Acerca de Kafka. Acerca de Freud. Barcelona: Anagrama, 1970. Seul, comme Franz Kafka. Paris: Calmann-Lévy, 1979.

Spiechowicz, Paulina. "Regards croisés. Kafka, le cadre et la chambre". K. Revue transeuropéenne de philosophie et arts 1 (2) (2018): 236-246.

Vogl, Joseph. Über das Zaudern. Zürich/Berlin: Diaphanes, 2008.

Zourabichvili, François. La littéralité et autres essais sur l'art. Paris: Presses Universitaires de France, 2011. 